\title{
Comparative Valuation of Precise and Approximate Non-Linear Models of an AC Discrete Voltage Regulator and Vector Analysis of Its Parameters
}

DOI: $10.46932 / \mathrm{sfjdv} 1 \mathrm{n} 4-003$

Received in: August 1st, 2020

Accepted in: September 30th, 2020

\section{Emil Stefanov Barudov}

Highest academic background: Assoc. Prof., PhD, Eng.

Current institution: Nikola Vaptsarov Naval Academy, Department of Electrical Engineering Full address (can be institutional or personal, as you prefer): 73 Vasil Drumev str., Varna 9002,

Bulgaria,

E-mail: ugl@abv.bg

\section{Emil Ivanov Panov}

Highest academic background: Assoc. Prof., PhD, Eng.

Current institution: Technical University of Varna, Department of Theoretical Electrical Engineering and Instrumentation

Full address (can be institutional or personal, as you prefer): 1 Studentska str., Varna 9010, Bulgaria E-mail: eipanov@yahoo.com

\begin{abstract}
The paper presents a review on the problems of the analysis of autotransformer discrete alternating voltage regulators. Most often the discrete regulation of $\mathrm{AC}$ voltages is achieved by power electronic converters based on a transformer (autotransformer) and switching by the means of controllable semiconductor switches.

The present work is dedicated to the comparison between precise and approximate non-linear models of autotransformer discrete alternating voltage regulator with changing input voltage and commutation angle of the semiconductor switches and to the vector measurements in an autotransformer discrete voltage regulator.
\end{abstract}

Keywords: AC voltage regulator, semiconductor switch, thyristor, vector analysis, vector measurements.

\section{INTRODUCTION}

In Fig. 1 the equivalent circuit of an autotransformer discrete AC voltage regulator (ADACVR) with four terminals and four controllable semiconductor switches (CSS) is shown. The equivalent circuit corresponds to the precise model where the circuit includes the parameters of the magnetic circuit, the commutation groups, the switch-off assemblies, the parameters of the separate sections of the winding and it takes into account the existing non-linearities. In the approximate non-linear model the losses in the autotransformer core are not considered, the semiconductor switches are accepted for ideal and the $\mathrm{RC}$ groups, which shunt the thyristors in the semiconductor switches, are not taken into account [1]. The adopted control algorithm is connected with switching at random moment as the commutation is always performed between two neighbouring semiconductor switches [2, 3]. 
The feeding with control pulses is suspended to the thyristor switch, which will be turned off (the switch remains conductive until the natural commutation of the thyristors inside it), and the other switch starts to be fed with control pulses. The equivalent circuits of the precise and approximate nonlinear models and their mathematical descriptions are presented in details in literature $[4,5]$.

The aim of the current work is the comparative research into the loading (the semiconductor switches, the autotransformer windings) by vector analysis and vector measurements of the quantities during the commutation process at different character of the load $-\mathrm{R}, \mathrm{RL}$ and $\mathrm{RC}$ and different commutation angles.

\section{ANALYSIS}

In this paper a vector analysis at low values of the input voltage of ADACVR is conducted. In this case, the switch $\mathrm{K}_{4}$ is turned off and the switch $\mathrm{K}_{3}$ is switched on (Fig.1).

Fig.1. Equivalent circuit corresponding to the precise model of an ADACVR with four CSS $\left(\mathrm{K}_{1} \div \mathrm{K}_{4}\right)$ at input voltage change.

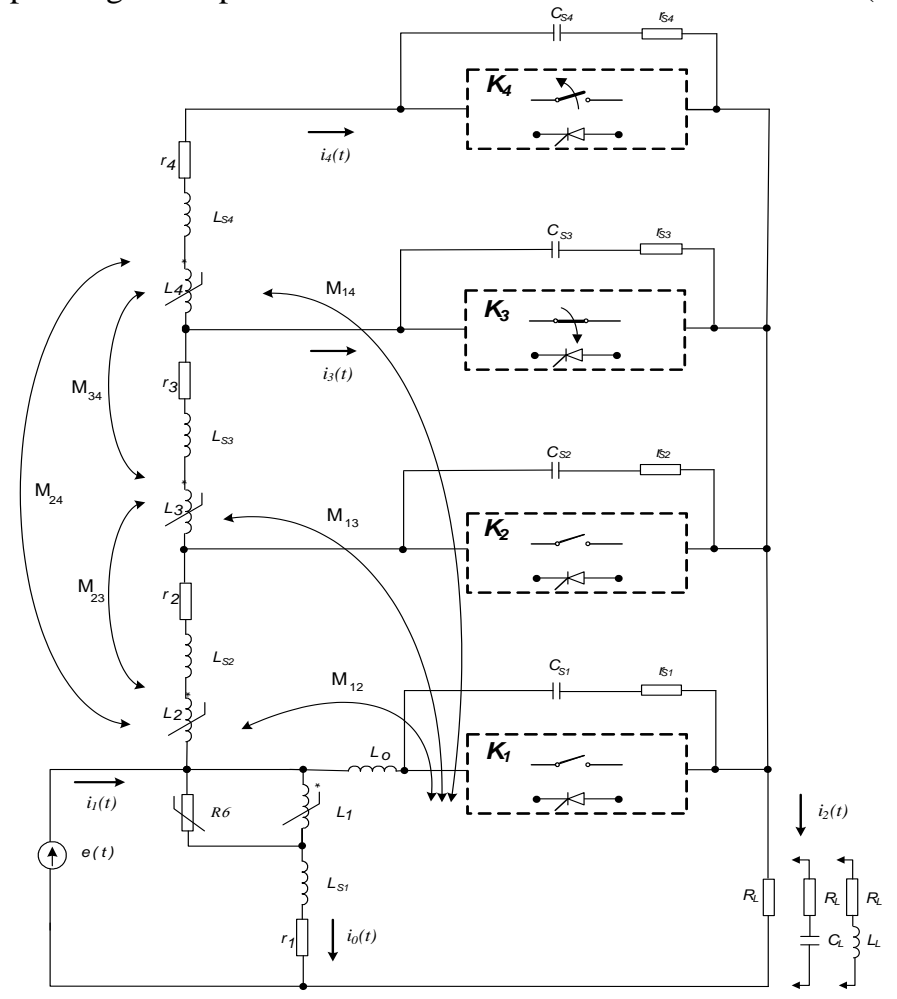

At the same time, at certain angles $\varphi$ of the commutation process, it is possible $\mathrm{r}_{4}$ and $\mathrm{L}_{4}$ (Fig. 1) to be connected in short circuit through two thyristors, one from the switch $\mathrm{K}_{4}$ and one from the switch $K_{3}$ respectively, for the time until the natural commutation of the switch $K_{4}$ occurs. This mode assumes an overload regime of the fourth section of the autotransformer and the two connected in series thyristors from the switches $\kappa_{4}$ and $\kappa_{3}$, when they are triggered. 


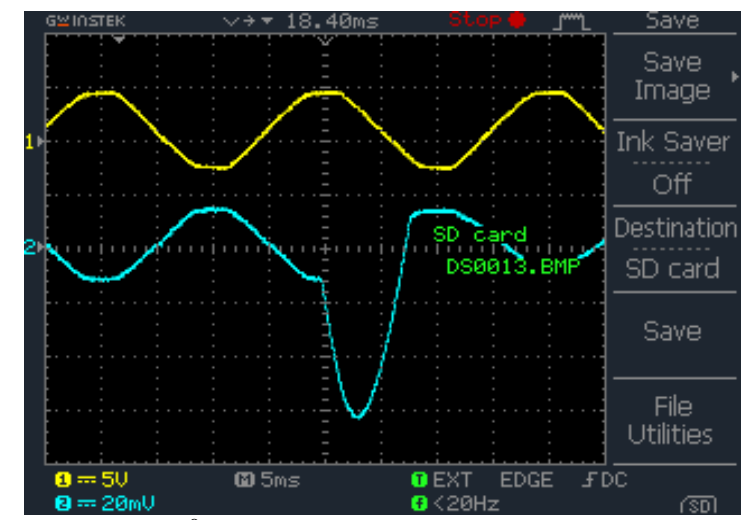

a) Oscillogram of the input current $i_{1}(t)$ at $\varphi=270^{\circ}$.

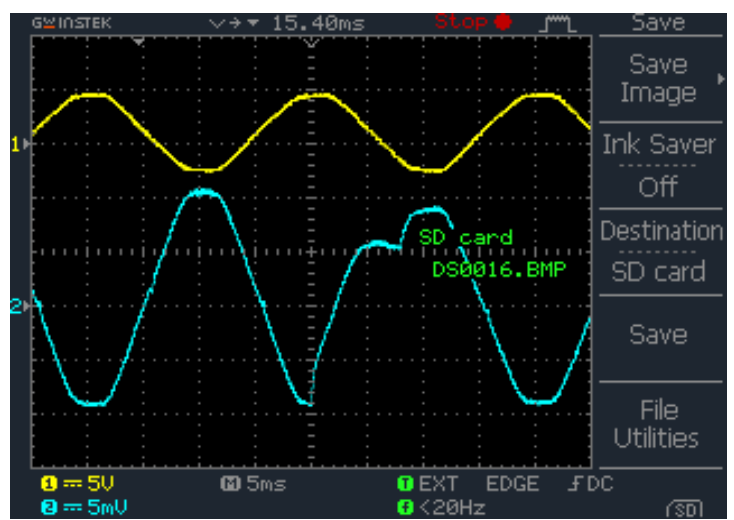

b) Oscillogram of the output current $i_{2}(t)$ at $\varphi=270^{\circ}$.

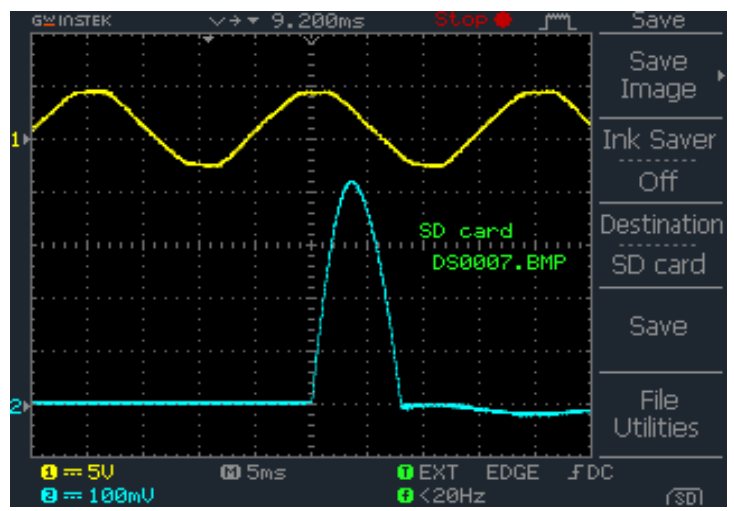

c) Oscillogram of the current through switch $\mathrm{K}_{3}-\mathrm{i}_{3}(\mathrm{t})$ at $\varphi=270^{0}$.

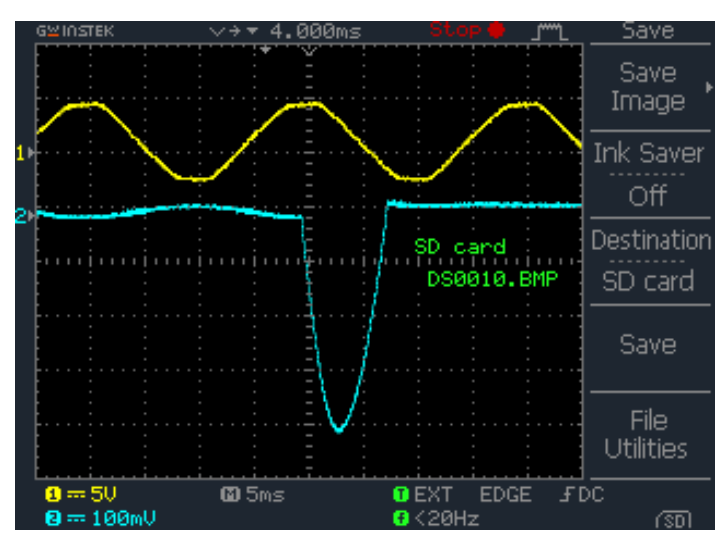

d) Oscillogram of the current through switch $\mathrm{K}_{4}-\mathrm{i}_{4}(\mathrm{t})$ at $\varphi=270^{0}$. 
Fig.2. Experimental oscillograms of the currents of the ADACVR for R load and commutation angle $\varphi=270^{0}$.

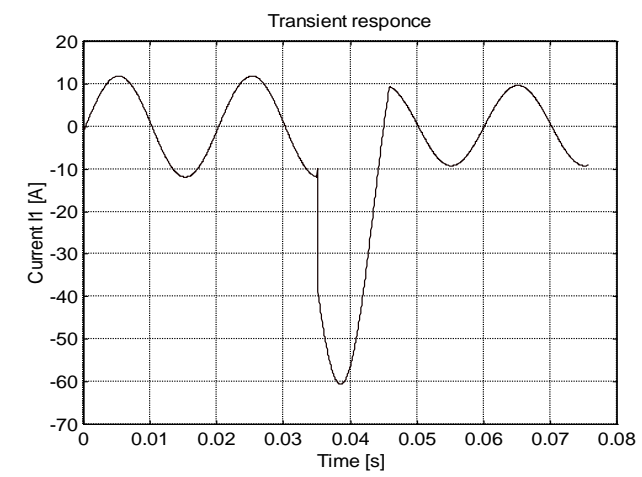

a) Simulation of the input current $i_{1}(t)$ at $\varphi=270^{\circ}$.

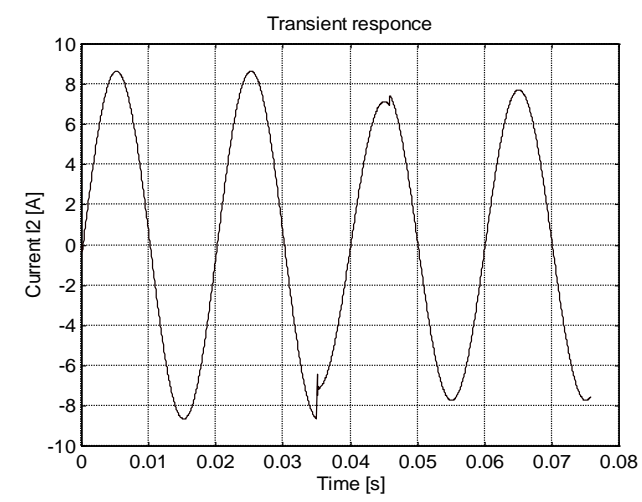

b) Simulation of the output current $i_{2}(t)$ at $\varphi=270^{\circ}$.

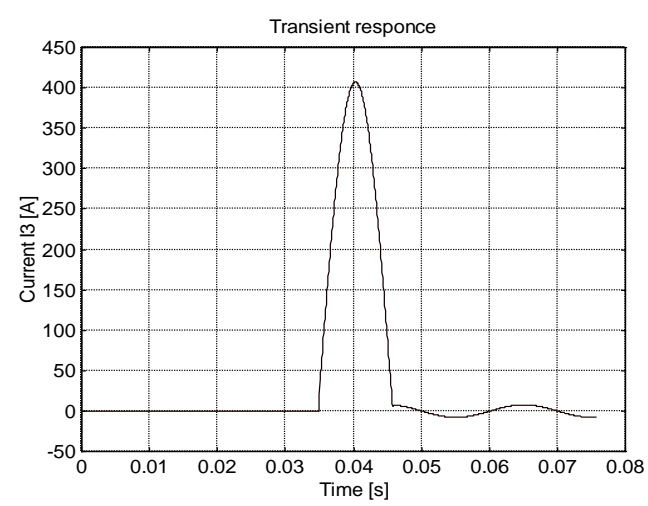

c) Simulation of the current through switch $K_{3}-i_{3}(t)$ at $\varphi=270^{\circ}$.

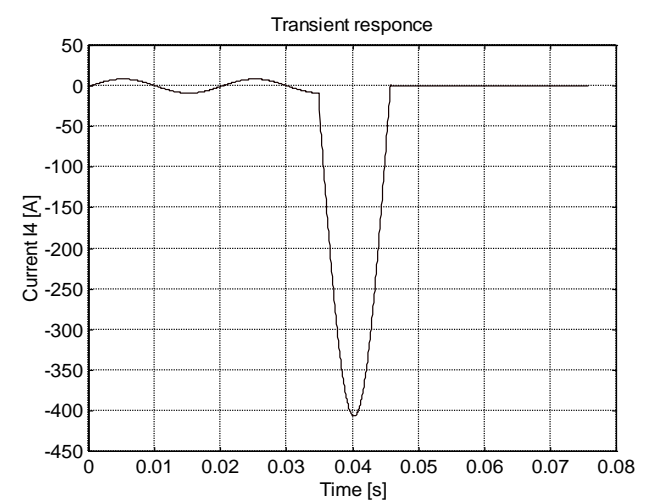

d) Simulation of the current through switch $\mathrm{K}_{4}-\mathrm{i}_{4}(\mathrm{t})$ at $\varphi=270^{\circ}$. 
a) Oscillogram of the input current $i_{1}(t)$ at $\varphi=225^{0}$
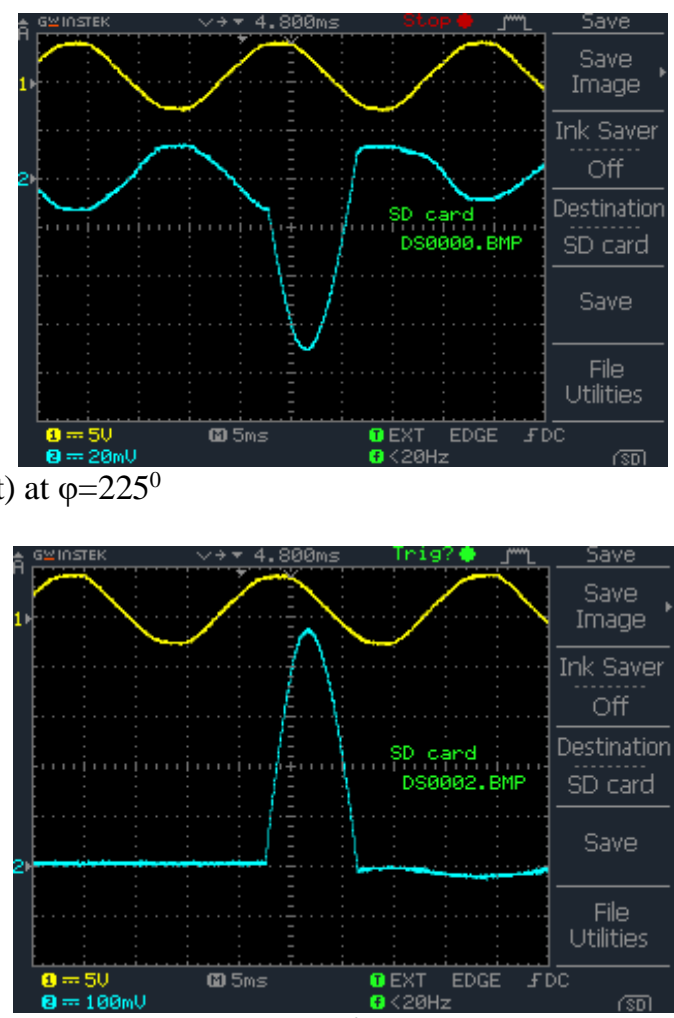

b) Oscillogram of the current through switch $K_{3}-i_{3}(t)$ at $\varphi=225^{0}$.

Fig.4. Experimental oscillograms of the currents of the ADACVR for RL load and commutation angle $\varphi=225^{0}$.

a) Oscillogram of the input current $i_{1}(t)$ at $\varphi=225^{0}$.
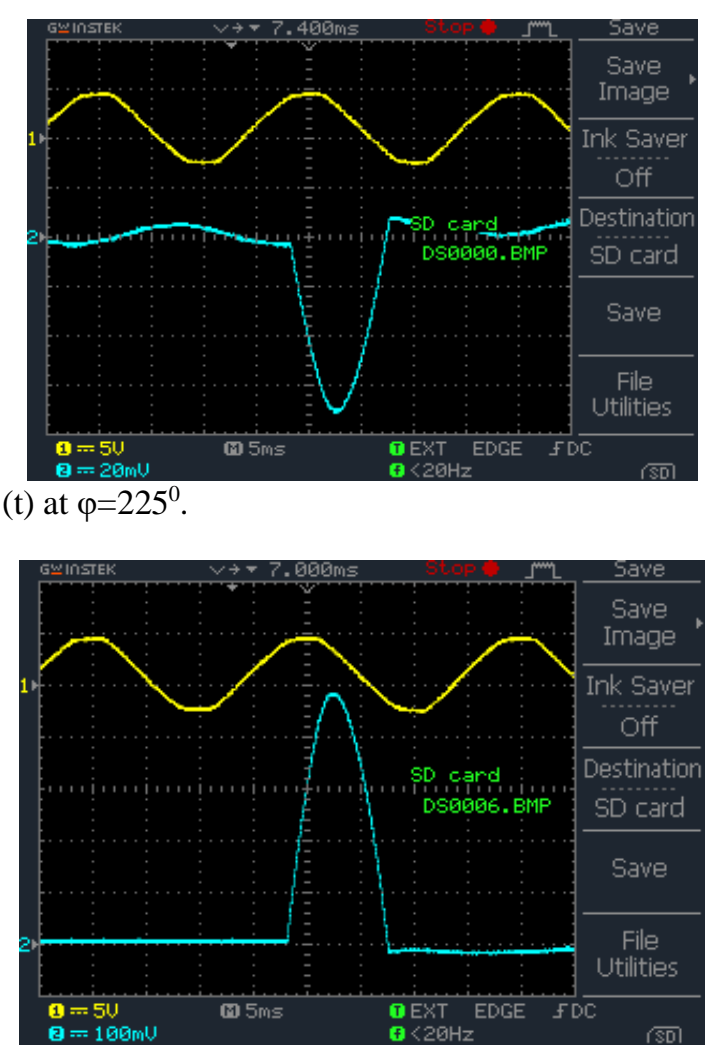

b) Oscillogram of the current through switch $K_{3}-i_{3}(t)$ at $\varphi=225^{0}$. 
Fig.6. Experimental oscillograms of the currents of the ADACVR for RC load and commutation angle $\varphi=225^{0}$.

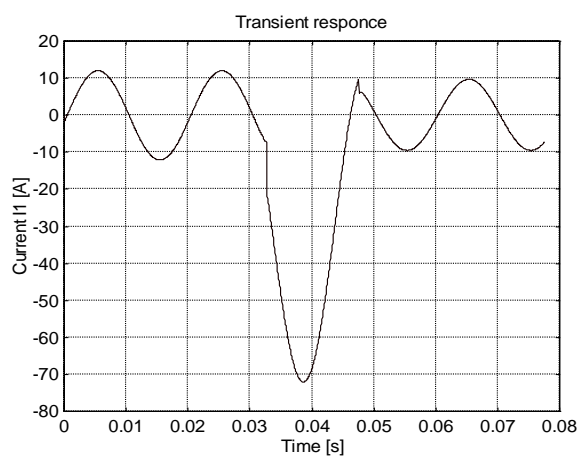

a) Simulation of the input current $i_{1}(t)$ at $\varphi=225^{0}$.

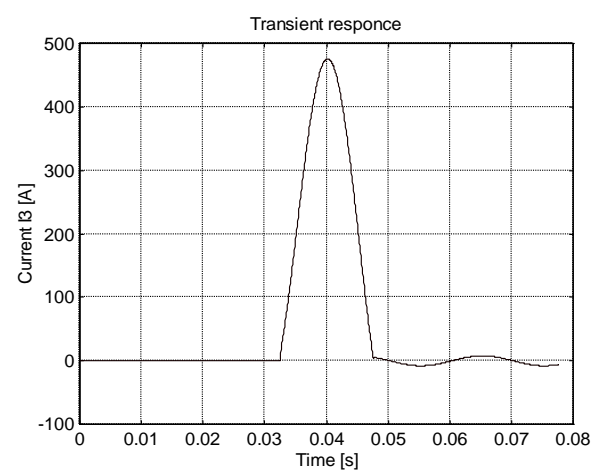

b) Simulation of the current through switch $K_{3}-i_{3}(t)$ at $\varphi=225^{0}$.

Fig.5. Computer simulation of the currents of the ADACVR for RL load and commutation angle $\varphi=225^{0}$.

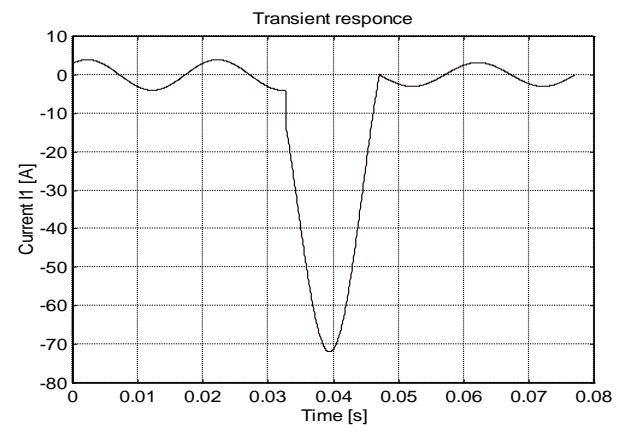

a) Simulation of the input current $i_{1}(t)$ at $\varphi=225^{0}$.

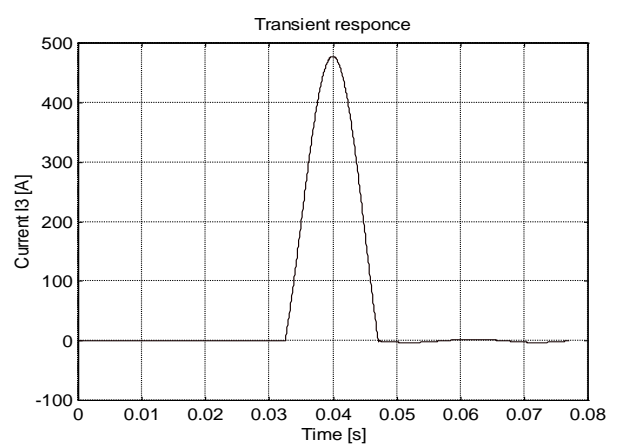

b) Simulation of the current through switch $K_{3}-i_{3}(t)$ at $\varphi=225^{0}$ 
Fig.7. Computer simulation of the currents of the ADACVR for RC load and commutation angle $\varphi=225^{0}$.

In case of an active load (R-load) and commutation angle $\varphi=270^{\circ}$, the results from the experimental oscillograms and the computer simulations with the programme AVTO (developed by the authors) in MATLAB integrated environment, are presented in Fig.2 and Fig.3. In cases of RL and RC loads, the development of the commutation process can be followed in Fig.4 and Fig.5, Fig.6 and Fig.7, respectively. The experimental oscillograms and simulations are taken at commutation angle $\varphi=225^{\circ}$.

The received experimental data for a concrete regime (closed switch $\mathrm{K}_{4}$ and opened switch $\mathrm{K}_{3}$ ) are shown in Table 1. The analytical data in the table are very close to those from the analysis of the precise model $[6,7,8,9,10]$. The numerical values from the simulations with the approximate model of the voltage regulator differ with average deviation $1 \%$ (minimum deviation $0,09 \%$ and maximum deviation $3 \%$ ) from those, received by a simulation with the precise model.

Table 1

\begin{tabular}{|c|c|c|c|c|c|c|}
\hline \multirow{2}{*}{$\begin{array}{c}\text { Type } \\
\text { of } \\
\text { load }\end{array}$} & \multicolumn{2}{|c|}{ Experimental data } & \multicolumn{3}{c|}{ Computer simulations } \\
\cline { 2 - 7 } & $I_{1}$ & $I_{2}$ & $U_{2}$ & $I_{1}$ & $I_{2}$ & $U_{2}$ \\
\cline { 2 - 7 } R & 8,45 & 6,16 & 219 & 8,3965 & 6,1205 & 218,6 \\
\hline RL & 9,75 & 7,03 & 219,9 & 8,5181 & 6,2016 & 217,8 \\
\hline RC & 2,85 & 2,15 & 220,3 & 2,8034 & 2,1421 & 222,6 \\
\hline
\end{tabular}

- Note: The loads for the experiments and the simulations, shown in the table, are as follows:

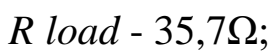

RL load - R-35,7 $, \mathrm{L}-1,76 \mathrm{H}$ (connected in parallel);

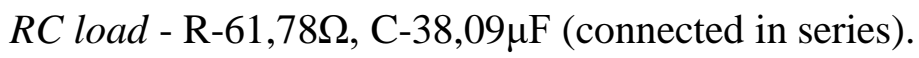

In Table 2 the vector quantities of the currents and the voltages of the autotransformer discrete regulator from the equivalent circuit in Fig. 1 are presented.

Table 2

\begin{tabular}{|l|l|l|l|}
\hline \multirow{3}{*}{$\begin{array}{l}\text { Type } \\
\text { load }\end{array}$} & \multicolumn{2}{l|}{$\begin{array}{l}\text { Results from vector measurements of } \\
\boldsymbol{A D A C V R}\end{array}$} \\
\cline { 2 - 4 } & $\dot{I}_{1}$ & $\dot{I}_{2}$ & $\dot{U}_{2}$ \\
\cline { 2 - 4 } & $\mathrm{A}$ & $\mathrm{A}$ & $\mathrm{V}$ \\
\hline R & $8,45 \mathrm{e}^{-\mathrm{j} 0,08}$ & $6,16 \mathrm{e}^{-\mathrm{j} 0,06}$ & 219 \\
\hline RL & $9,75 \mathrm{e}^{-\mathrm{j} 0,14}$ & $7,03 \mathrm{e}^{-\mathrm{j} 0,12}$ & $219,9 \mathrm{e}^{\mathrm{j} 0,06}$ \\
\hline RC & $2,85 \mathrm{e}^{\mathrm{j} 0,89}$ & $2,15 \mathrm{e}^{\mathrm{j} 0,92}$ & $219 \mathrm{e}^{-\mathrm{j} 0,01}$ \\
\hline
\end{tabular}




\section{CONCLUSION}

A programme AVTO in MATLAB integrated environment is developed, and it allows visualization of the computer simulations as well as examination of the discrete AC voltage regulator with different loads and parameters of the commutation processes.

A vector analysis and vector measurements of the quantities, referred to the commutation and the regimes in a power semiconductor converter with discrete regulation of the input AC voltage magnitude to the joined consumers have been conducted. A precise and approximate (with certain simplifications) models have been examined at different angles for the commutation process and for different loads.

An approximate non-linear model can be used for a quick engineering calculation of an autotransformer discrete AC voltage regulator with different number of terminals.

Both results - from the experiments and from the computer simulations, show a very good match of the obtained results.

\section{REFERENCES}

[1] Harlow James H., Transformers. The Electric Power Engineering Handbook. Ed. L.L. Grigsby Boca Raton: CRC Press LLC, 2001.

[2] Fernando S., Power Electronics Handbook - voltage regulators. (Third Edition), Sónia Ferreira Pinto, 2011.

[3] Barudov S. and Barudov E., Discrete Alternating Current Regulators and Stabilizers. Sofia-Moscow, Pensoft, 2006, 127 pages. ISBN 978-954-642-276-7

[4] Barudov E., Panov E., Barudov S., Analysis of Electrical Processes in Alternating Voltage Control Systems. Journal of International Scientific Publication: Materials, Methods \& Technologies, Vol. 4,

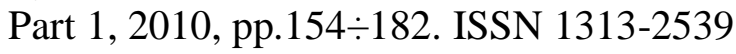

[5] Barudov E., Panov E., Barudov S., Exploration of Precise Non-Linear Model of Discrete Autotransformer Step-Voltage AC Regulator with Semiconductor Commutators. Annual of TU-

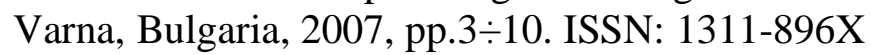

[6] Barudov E., Panov E., Barudov S., Analysis of Electrical Processes in a Discrete Alternating Voltage Regulator with Active-Capacitive Load. Proceedings of the International Scientific and Technical Conference "Electrical Power Engineering 2010", Varna, Bulgaria, 2010, pp.332 $\div 341$. ISBN 978-954-20-0497-4

[7] Barudov E., Panov E., Barudov S., Analysis of Electrical Processes in a Discrete Alternating

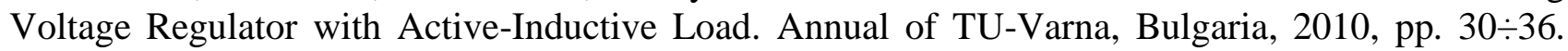
ISSN: 1311-896X

[8] Panov, E., Barudov, E., and Ivanova, M. Exploration of the Electric Processes in Discrete Alternating Step-Voltage Regulators. Proceedings of the $\mathrm{XX}^{\text {-th }}$ International Symposium on 


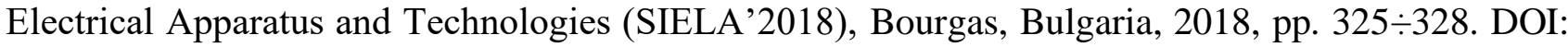
10.1109/SIELA.2018.8447122, Electronic ISBN: 978-1-5386-3419-6

[9] Panov E., Ivanova M., and Barudov E., Study of the electrical characteristics of autotransformer discrete alternating voltage regulators with R-L loads. Proceedings of the $\mathrm{XVI}^{\text {th }}$ International Conference on Electrical Machines, Drives and Power Systems (ELMA'2019), Varna, Bulgaria, 2019 , pp. $321 \div 325$. ISBN 978-1-7281-1412-5

[10] Barudov, E. Panov, E. Barudov, and M. Ivanova, Discrete Stabilizer of AC Voltage. Patent BG1727 U1/07.08.2013. (in Bulgarian) 